Check for updates

Cite this: RSC Adv., 2021, 11, 22751

Accepted 22nd June 2021

DOI: $10.1039 / \mathrm{d} 1 \mathrm{ra03769b}$

rsc.li/rsc-advances

\section{Boric acid in magnetized water: clean and powerful media for synthesis of 3,4-dihydropyrimidin-2(1H)- ones $\dagger$}

\author{
Vahid Khakyzadeh, (D) *a Ahmad Reza Moosavi-Zare, (D) ${ }^{\mathrm{b}}$ Sahra Sheikhaleslami, ${ }^{\mathrm{a}}$ \\ Amir Ehsani, ${ }^{a}$ Salbin Sediqi, ${ }^{a}$ Mohammad Rezaei-Gohar ${ }^{\mathrm{b}}$ and Zahra Jalilian ${ }^{\mathrm{c}}$
}

\begin{abstract}
Water was magnetized via an external magnetic field and employed, for the first time, as a solvent in green preparation of 3,4-dihydropyrimidin-2(1H)-ones by the one-pot three-component condensation reaction using boric acid as a catalyst. Shorter reaction times, higher yields, and cleaner reaction profiles were some advantages of using magnetic water.
\end{abstract}

It is well-known that water is the most crucial matter in nature, thus in numerous papers, physical and chemical properties of water and also their changes under actions of external factors like electromagnetic fields have been investigated, ${ }^{1}$ although the principle of magnetic field (MF) treatment on the water is still a controversial subject, and no clear mechanisms of this effect have been reported in the literature. ${ }^{2}$ Many studies have indicated that the physicochemical properties of water change by passing through the $\mathrm{MF}^{3}$ for example, inter- and intracluster hydrogen bonds, coagulation, polymorphism of the crystals, the zeta potential of the precipitated or dispersed particles, viscosity, diffusivity, surface tension, friction coefficient, $\mathrm{pH}$ values, electrical conductivity, and some physical properties of water, including specific heat, evaporation amount and boiling point. ${ }^{4}$ Owing to the changes in physicochemical properties, magnetic water has been utilized mainly for agriculture, wastewater treatment, industry, and construction. ${ }^{5}$ The magnetization of water and its effectiveness on the physical and chemical properties of water depends on several factors including, magnetization and exhibition of a magnetic field, magnetic gradient, Lorentz force, and magnetic memory. ${ }^{6}$ Three mechanisms have been proposed for how the magnetic field affects water particles: (I) the spontaneous formation and collapse of cationic metal colloidal units in the interaction of magnetism and water, which leads to increase sedimentation in water; (II) the change in polarization of the dissolved ions in the water, the shape and size of the hydration layer cause some variations in the water properties; and (III) due to the polarity of

${ }^{a}$ Department of Chemistry, K. N. Toosi University of Technology, P.O. Box 16315-1618, 15418 Tehran, Iran.E-mail:v.khakyzadeh@kntu.ac.ir

${ }^{b}$ Hamedan University of Technology, Department of Chemistry, Hamedan, 65155, Iran

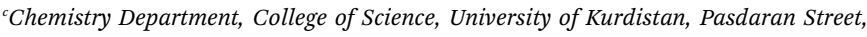
Sanandaj, 66177-15177, Iran

$\dagger$ Electronic supplementary information (ESI) available. See DOI: $10.1039 / \mathrm{d} 1 \mathrm{ra} 03769 \mathrm{~b}$ the water molecules, the magnetic field will directly affect the nature of the water molecules, the third mechanism is largely consistent with the experiments performed. ${ }^{7}$ Recently, few research groups such as Alabi, Zuniga, and Rodgers have started to examine the magnetic field effects on chemical reactions and their consequences in yield and rate of reaction or product distribution. It was considered that these effects might be performed via the radical pair mechanism. ${ }^{8}$

Encouraged by previous works in the application of magnetic water, we decided to produce and employ magnetic water as a solvent in some interesting organic reactions. ${ }^{9}$ The multicomponent condensation reactions are valuable protocols for synthesizing desired compounds in one step without the separation of any intermediates in organic chemistry. ${ }^{10}$ In this chemical strategy, some beneficial features are high yields, shorter reaction times, high atomic economy, and low waste materials and energy consumption. ${ }^{11}$ So staying in this direction can bring us closer to the goals of green chemistry. ${ }^{12}$ Preparation of 3,4-dihydropyrimidin-2(1H)-one (DHPMs) is significant due to their therapeutic and pharmacological properties, for example; Batzelladine, found in marine natural alkaloids, as an HIV inhibitor, ${ }^{13 a}$ also monastrol, ${ }^{13 b}$ and SQ $32926,{ }^{13 c}$ have been explained as synthetic or natural DHPs with biological properties (Scheme 1). The Biginelli reaction was reported for the first time by Pietro Biginelli. ${ }^{14}$ In this reaction, 3,4-dihydropyrimidin-2(1H)-ones (DHPMs) were prepared by a three-component condensation reaction of aldehyde, urea,

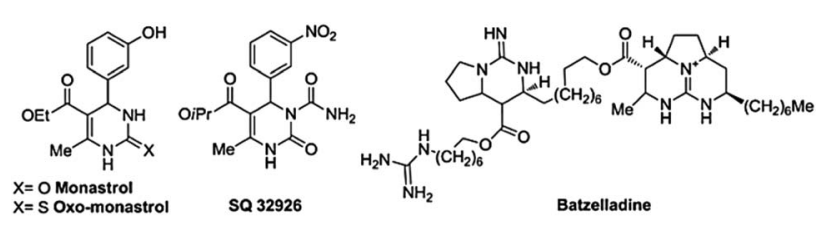

Scheme 1 DHPMs containing natural or synthetic parts. 


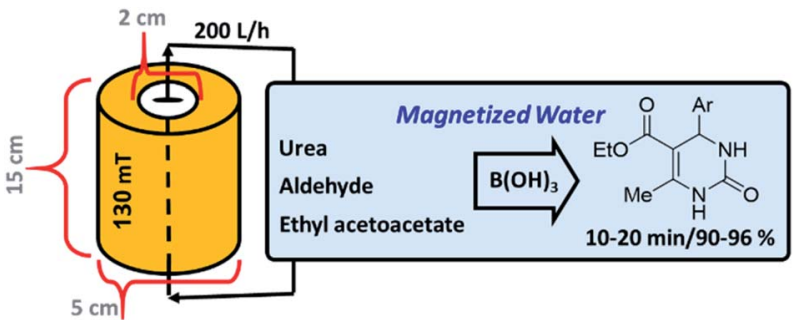

Scheme 2 The one-pot three-component preparation of 3,4-dihydropyrimidin-2(1H)-ones in magnetized water/B $(\mathrm{OH})_{3}$ system.

and ß-ketoester as interesting compounds with a potential for pharmaceutical applications. Various catalysts were reported for this reaction such as, $[\mathrm{bmim}]\left[\mathrm{MeSO}_{4}\right],{ }^{15} \mathrm{FeCl}_{3},{ }^{16} \mathrm{RuCl}_{3},{ }^{17} \mathrm{TMSCl},{ }^{18}$ $\mathrm{ZrSA}^{19}$ and [H-NMP $]\left[\mathrm{CH}_{3} \mathrm{SO}_{3}\right]{ }^{20}$ Due to the important properties of these compounds, finding the new protocols for the synthesis of 3,4-dihydropyrimidin-2(1H)-ones are still needed.

Nowadays, many reactions need catalysts to carry out. Among many kinds of them, organocatalysts have attracted much attention. They are well-known as artificial catalysts for these plans. In comparison with inorganic catalysts and enzymes, they are not complicated, regularly less toxic, and widely available. ${ }^{21}$ Boric acid, as an organocatalyst, aqueous solution system, is one of the efficient and green catalytic systems in organic chemistry. Boric acid was successfully utilized in the preparation of different organic compounds such as, pyrano[2,3- $d$ ] pyrimidine diones, ${ }^{22}$ tetrahydrobenzo $[b]$ pyrans, ${ }^{23} N, N^{\prime}$-alkylidene bisamides, ${ }^{24} \quad 4 H$-isoxazol-5-ones, ${ }^{25} \quad$ 2-arylamino-2-phenylacetamide ${ }^{26}$ bis(indolyl)methanes. ${ }^{27}$ In these mild conditions, $\mathrm{H}^{+}$, which is abstracted from water by the interaction with $\mathrm{B}(\mathrm{OH})_{3}$, efficiently catalyzes the reaction, ${ }^{22,23}$ and water as a solvent plays a key role in these reactions. In water molecules, the non-uniform distribution of electrons leads to the creation of positive and negative particle charges. Based on points mentioned earlier, we wondered to evaluate the effect of magnetized water as a solvent and also using boric acid as a catalyst, on the synthesis of 3,4dihydropyrimidin-2(1H)-one derivative (Scheme 2).

To prepare magnetic water, a cylindrical system with an approximate capacity of $100 \mathrm{~mL}$ was filled with neodymium supermagnets (Nd), which generated a magnetic field of $130 \mathrm{mT}$ at the center and diameter of the tube, was used to construct the reactor of magnetic water. The water used in the system was distilled twice by the Prima30 machine and circulated in the system by a (SEBO P280) pump with a power of 200 liters per hour, and after 8 hours, the water became magnetic. After the preparation of magnetic water, some main physicochemical properties, such as viscosity, gas solubility, refractive index, surface tension, $\mathrm{pH}, \mathrm{UV}$-visible and FT-IR analysis, were evaluated.

Initially, the oxygen gas solubility in magnetic and ordinary water was measured by Winkler method based on standard method procedure. ${ }^{28}$ After photometric testing, it was found that the solubility of oxygen in magnetic water was slightly higher than in ordinary water (MW : $n$-MW $=8: 7 \mathrm{ppm})$. We suggested that probably the paramagnetism of oxygen structure, as well as the molecular orbital of oxygen, can be effective in presenting this result. A paramagnetic structure with magnetic properties is more soluble in a magnetized solvent. ${ }^{29}$ Next, the viscosity, as an essential factor in the efficiency of organic reaction, was measured at different temperatures according to the reference method. ${ }^{30}$ The results determined that the viscosity of magnetic water was generally slightly lower than ordinary distilled water. Based on our observations, it was found that the viscosity differences were higher at low temperatures, indicating that at high temperatures, the hydrogen bonds are almost weakened and results in no significant differences between the viscosity of magnetic water and ordinary water. In contrast, at low temperatures, because of the high number of intra-cluster bonds in ordinary water, they form a colloidal bulk structure that increases its viscosity. The intermolecular structure of the magnetic water molecules is hexagonal layers that are interconnected by inter-cluster hydrogen bonds, which form a graphite-like structure and gives a particular softness to the water and reducing its viscosity (Fig. 1a). ${ }^{31}$ This property could be effective in running the organic reaction. Moreover, the refractive index of magnetic water and nonmagnetic water was also evaluated by a refractometer at different temperatures. It was found that at low temperatures, the refractive index of magnetic water was approximately the same as distilled water, whereas, at higher temperatures, the refractive index of magnetic water was lower than ordinary water. To justify this observation, it can be noted that magnetic water has a more stable structure than ordinary water, and this somewhat stable structure limited waste fractures when the photons traveled through the water (Fig. 1b). Interestingly, our results were contrary to Hosoda et al. who showed magnetic water has a higher refractive index. ${ }^{32}$ They explained that it is because of the lifetime of the $\mathrm{H}$-bonds. $\mathrm{pH}$ measurements can also be evaluated as a criterion for investigating hydrogen bond clusters. For this issue in mind, the $\mathrm{pH}$ changes of the water were measured at different temperatures. It was found that the acidity of the magnetic water was lower than ordinary water, and the difference between their $\mathrm{pH}$ enhanced with increasing temperature (Fig. 1c). Surface tension analysis for magnetized water and distilled water showed that ordinary water has a higher surface tension in different
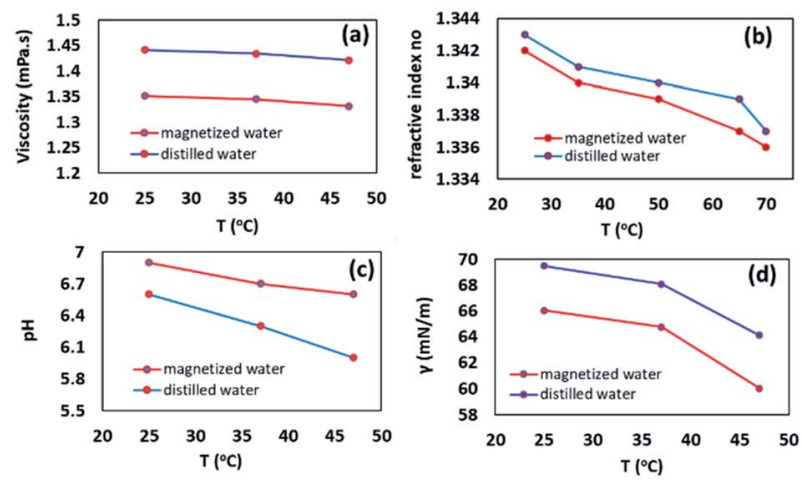

Fig. 1 The viscosity, refractive index, $\mathrm{pH}$ measurements, and surface tension analysis for magnetic and distilled water in different temperatures. 


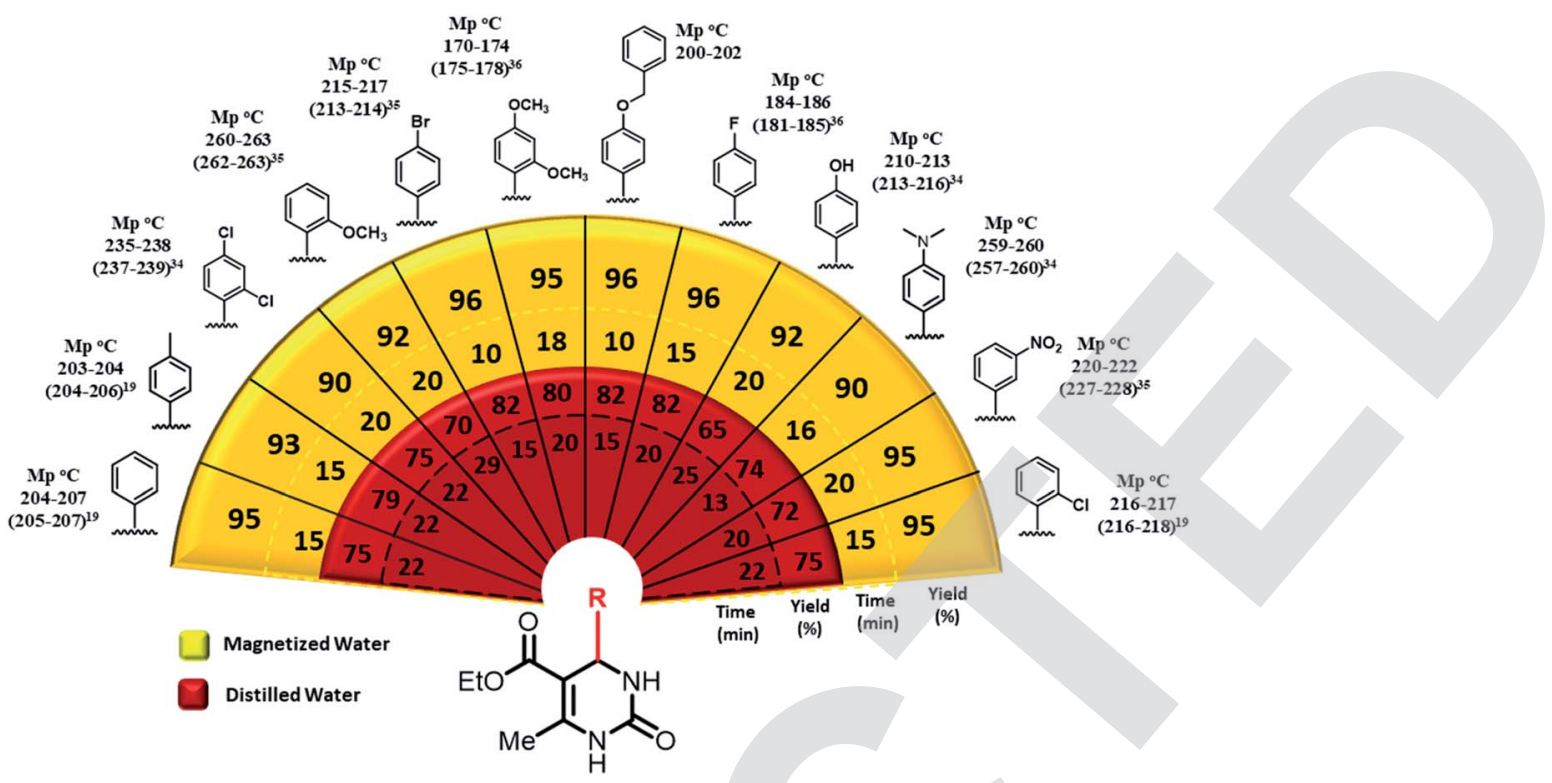

Fig. 2 Scope of the synthesis of 3,4-dihydropyrimidin-2(1H)-ones in magnetized and distilled water as solvent under optimized condition. ${ }^{19,34-36}$

temperatures rather than magnetic water which was in good agreement with Cho's report that magnetic field reduced the surface tension of natural water by about $8 \%$ (Fig. 1d). ${ }^{33}$

Eventually, for examining the optical properties of magnetic and ordinary water, IR and UV analyses were performed. No significant difference was detected in the UV spectra (ESI, S1†), but, interestingly, in the IR spectra, some peaks were weakened or disappeared, and some new peaks were observed (ESI, S2 $\dagger$ ). There are two differences in comparing ordinary and magnetic water IR spectra: (I) the detection of Peaks 2923.53 and 2853.03 is probably due to internal structural patterns of $\mathrm{H}_{2} \mathrm{O}$ molecules and/or hydrogen bond chain in ordinary water which in magnetic water these peaks are very weakened or not seen due to the new structural patterns of water molecules; (II) in the 1709.69 region, a new peak was detected in the magnetic water spectrum compared to ordinary water, which was attributed to the transition of the water phase from a complex irregular spherical structure to a regular hexagonal ring structure in magnetic water (Fig. 3).

After preparation and characterization of magnetic water, we wonder to investigate the preparation of 3,4-dihydropyrimidin$2(1 H)$-ones using boric acid, in nonmagnetic water and also magnetic water as solvent under reflux conditions. To find

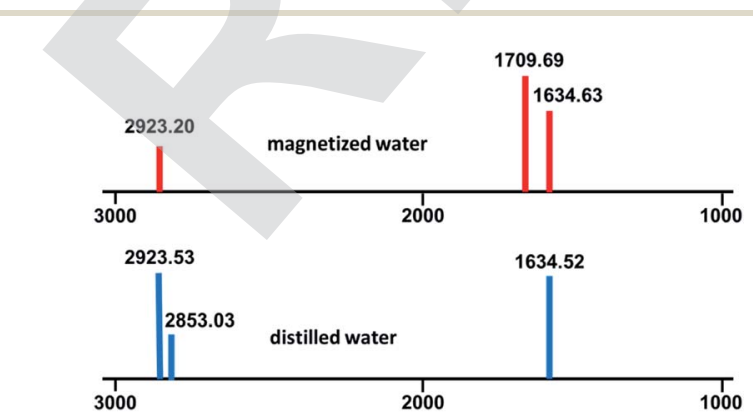

Fig. 3 Schematic diagram of the FTIR spectroscopy of magnetized and distilled water. optimized conditions, we have chosen the reaction of ethyl acetoacetate $(1 \mathrm{mmol})$, urea $(1 \mathrm{mmol})$, and benzaldehyde $(1$ $\mathrm{mmol}$ ) as a model reaction (Table 1 ).

This reaction was investigated in the presence of different amounts of boric acid at temperatures ranging between $25^{\circ} \mathrm{C}$ and $100{ }^{\circ} \mathrm{C}$ under aqueous conditions (entry 1-12). At first, in the model reaction without catalyst and solvent at $80^{\circ} \mathrm{C}$, a trace yield was observed (entry 1 ). Then we checked different amounts of the boric acid as a catalyst (entry 2-5, 3-15 mol\%) in water, and $75 \%$ of desired product was seen when we employed a $15 \mathrm{~mol} \%$ catalyst. After that, the reaction was carried out at different temperatures (entry 6-8). No improvement was recognized at $100{ }^{\circ} \mathrm{C}$. Next, magnetized water was employed as a solvent in the model reaction with a similar condition of entry 5 . Interestingly, shorter reaction time and higher yield were obtained (entry 9, $15 \mathrm{~min}$ : 95\%), compared to distilled water and ethanol. Moreover, the model reaction was evaluated in some organic solvents such as $n$-hexane, dichloromethane, and ethanol under reflux conditions compared with water, no better results were seen (entry 10-12).

To investigate the efficacy and generality of boric acid in the synthesis of 3,4-dihydropyrimidin-2(1H)-ones, various aryl aldehydes were reacted with ethyl acetoacetate and urea using boric acid aqueous solution (magnetized water and distilled water) system under the optimal reaction conditions to obtain the desired products in high yields and in short reaction times. The highest reaction yields have been detected in para-substituted aryl aldehydes with halogen [-F (96\%), - $\mathrm{Cl}(96 \%),-\mathrm{Br}(96 \%)]$, whereas disubstituted aryl aldehyde with halogen has shown the lowest reaction yield (90\%). Also, aryl aldehydes with electron-donating substitutions displayed lower reaction yields [-OH (92\%), $\left.-\mathrm{OCH}_{3}(92 \%)\right]$ (Fig. 2).

The acidity of the aqueous boric acid solution is exclusively due to the reaction of boric acid with water to prepare $\mathrm{B}(\mathrm{OH})_{4}{ }^{-}$. It can release of $\mathrm{H}^{+}$in the aqueous solution. ${ }^{22,23}$ In the proposed mechanism, which is supported by the literature, ${ }^{19,20,30-32}$ at first, 
Table 1 The effect of catalyst amounts, temperature, and various solvents on the reaction of ethyl acetoacetate, urea, and benzaldehyde as a model reaction

\begin{tabular}{lclcl}
\hline Entry $^{a}$ & Catalyst (mol\%) & Solvent & Time (min) & Yield $^{b}(\%)$ \\
\hline 1 & - & - & 180 & Trace \\
2 & 3 & $\mathrm{H}_{2} \mathrm{O}$ & 55 & 45 \\
3 & 5 & $\mathrm{H}_{2} \mathrm{O}$ & 40 & 50 \\
4 & 10 & $\mathrm{H}_{2} \mathrm{O}$ & 30 & 60 \\
5 & 15 & $\mathrm{H}_{2} \mathrm{O}$ & 22 & 75 \\
6 & 15 & $\mathrm{H}_{2} \mathrm{O}^{c}$ & 60 & 25 \\
7 & 15 & $\mathrm{H}_{2} \mathrm{O}^{d}$ & 40 & 45 \\
8 & 15 & $\mathrm{H}_{2} \mathrm{O}^{e}$ & 22 & 78 \\
9 & 15 & $\mathrm{~m}^{-} \mathrm{H}_{2} \mathrm{O}$ & 15 & 95 \\
10 & 15 & $n-\mathrm{Hexane}$ & 40 & 15 \\
11 & 15 & $\mathrm{CH}_{2} \mathrm{Cl}$ & 40 & 35 \\
12 & 15 & Ethanol $^{2}$ & 35 & 80
\end{tabular}

${ }^{a}$ Reaction was caried out at $80{ }^{\circ} \mathrm{C} .{ }^{b}$ Isolated yield. ${ }^{c}$ At $=25{ }^{\circ} \mathrm{C} .{ }^{d}$ At $=$ $50{ }^{\circ} \mathrm{C} .{ }^{e}$ At $=100{ }^{\circ} \mathrm{C}$.

ethyl acetoacetate was reacted with aldehyde which was activated by produced $\mathrm{H}^{+}$and afforded an intermediate as a Michael acceptor after removing one molecule of $\mathrm{H}_{2} \mathrm{O}$. Then, the desired product was generated by the reaction of urea with aforesaid intermediate.

An interesting observation during the reaction was the lower solubility of the desired products when the solvent was magnetized water. This feature led to better purification of products.

\section{General Procedure for the synthesis of 3,4-dihydropyrimidin-2(1H)-ones}

A mixture of ethyl acetoacetate $(1 \mathrm{mmol})$, urea $(1 \mathrm{mmol})$, aryl aldehyde (1 mmol), $\mathrm{B}(\mathrm{OH})_{3}(15 \mathrm{~mol} \%)$ and water/magnetized water $(3 \mathrm{~mL})$ was added in a $25 \mathrm{~mL}$ round-bottomed flask connected to a reflux condenser and stirred under reflux condition. After completion of the reaction, as monitored by TLC, the reaction mixture was cooled to room temperature and desired product recrystallized from ethanol.

\section{Conclusions}

Herein, we have investigated the employment of magnetized water as a reaction media to prepare 3,4-dihydropyrimidin-2(1H)-ones by a one-pot three-component condensation reaction using a boric acid catalyst and compared the results with non-magnetic media for the first time. Interestingly, applying magnetized water under reflux conditions resulted in higher yields and shorter reaction times.

\section{Conflicts of interest}

There are no conflicts to declare.

\section{Acknowledgements}

We thank K. N. Toosi University of Technology, Tehran, Iran and Hamedan University of Technology, for financial support of the presented work.

\section{Notes and references}

1 (a) X. F. Pang and B. Deng, Phys. B, 2008, 403, 3571-3577; (b) X. Han, Y. Peng and Z. Ma, Optik, 2016, 127, 6371-6376; (c) L. Holysz, A. Szczes and E. Chibowski, J. Colloid Interface Sci., 2007, 316, 996-1002; (d) M. C. Amiri and A. A. Dadkhah, Colloids Surf., A, 2006, 278, 252-255; (e) Y. Wang, B. Zhang, Z. Gong, K. Gao, Y. Ou and J. Zhang, J. Mol. Struct., 2013, 1052, 102-104.

2 (a) R. Cai, H. Yang, J. He and W. Zhu, J. Mol. Struct., 2009, 938, 15-19; (b) I. Ignatov and O. Mosin, Eur. J. Mol. Biotechnol., 2014, 4, 72-85.

3 Y. Wang, H. Wei and Z. Li, Results Phys., 2018, 8, 262-267.

4 (a) E. Chibowski, A. Szcześ and L. Hołysz, Colloids Interfaces, 2018, 2, 68; (b) E. J. Toledo, T. C. Ramalho and Z. M. Magriotis, J. Mol. Struct., 2018, 888, 409-415; (c) K. T. Chang and C. I. Weng, J. Appl. Phys., 2006, 100, 043917. 5 (a) S. Kobe, G. Dražić, P. J. McGuiness and J. Stražišar, J. Magn. Magn. Mater., 2001, 236, 71-76; (b) M. E. Maffei, Front. Plant Sci., 2014, 5, 445; (c) H. Wei, Y. Wang and J. Luo, Constr. Build. Mater., 2017, 147, 91-100; (d) I. Vaskina, I. Roi, L. Plyatsuk, R. Vaskin and O. Yakhnenko, Journal of Ecological Engineering, 2020, 21, 251-260.

6 (a) N. S. Zaidi, J. Sohaili, K. Muda and M. Sillanpä, Sep. Purif. Rev., 2014, 43, 206-240; (b) T. Panczyk and P. J. Camp, J. Mol. Liq., 2021, 330, 115701; (c) M. Colic and D. Morse, Colloids Surf., A, 1999, 154, 167-174; (d) Y. Z. Guo, D. C. Yin, H. L. Cao, J. Y. Shi, C. Y. Zhang, Y. M. Liu, H. H. Huang, Y. Liu, Y. Wang, W. H. Guo and A. R. Qian, Int. J. Mol. Sci., 2012, 13, 16916-16928.

7 E. Chibowski and A. Szcześ, Chemosphere, 2018, 203, 54-67. 8 (a) C. T. Rodgers, Pure Appl. Chem., 2009, 81, 19-43; (b) A. Alabi, M. Chiesa, C. Garlisi and G. Palmisano, Environ. Sci.: Water Res. Technol., 2015, 1, 408-425; (c) L. Lin, W. Jiang, X. Xu and P. Xu, npj Clean Water, 2020, 3, 1-19; (d) O. Zúñiga, J. A. Benavides, D. I. Ospina-Salazar, C. O. Jiménez and M. A. Gutiérrez, Ing. Compet., 2016, 18, 217-232.

9 V. Khakyzadeh, R. Luque, M. A. Zolfigol, H. R. Vahidian, H. Salehzadeh, V. Moradi, A. R. Soleymani, A. R. MoosaviZare and K. Xu, RSC Adv., 2015, 5, 3917-3921.

10 (a) A. Khazaei, A. R. Moosavi-Zare, H. Afshar-Hezarkhani and V. Khakyzadeh, RSC Adv., 2014, 4, 32142; (b) A. Khazaei, F. Gholami, V. Khakyzadeh, A. R. Moosavi-Zare and J. Afsar, RSC Adv., 2015, 5, 14305.

11 A. R. Moosavi-Zare, M. A. Zolfigol and M. Daraei, Synlett, 2014, 25, 1173.

12 A. R. Moosavi-Zare, M. A. Zolfigol, F. Derakhshan-Panah and S. Balalaie, Mol. Catal., 2018, 449, 142.

13 (a) A. D. Patil, N. V. Kumar, W. C. Kokke, M. F. Bean, A. J. Freyer, C. D. Brosse, S. Mai, A. Truneh and B. Carte, J. Org. Chem., 1995, 60, 1182; (b) D. Russowsky, R. F. Canto, S. A. Sanches, M. G. D'oca, A. De Fatima, R. A. Pilli, L. K. Kohn, M. A. Antônio and J. E. De Carvalho, Bioorg. Chem., 2006, 34, 173; (c) K. S. Atwal, B. N. Swanson, S. E. Unger, D. M. Floyd, S. Moreland, A. Hedberg and B. C. O'Reilly, J. Med. Chem., 1991, 34, 806. 
14 C. O. Kappe, The Biginelli Reaction, in Multicomponent Reactions, ed. J. Zhu and H. Bienaymé, Wiley-VCH, Weinheim, ISBN 978-3-527-30806-4, 2005.

15 S. R. Roy, P. S. Jadhavar, K. Seth, K. K. Sharma and A. K. Chakraborti, Synthesis, 2011, 2261.

16 I. Cepanec, M. Litvic, A. Bartolincic and M. Lovric, Tetrahedron, 2005, 61, 4275.

17 J. H. Schauble, E. A. Trauffer, P. P. Deshpande and R. D. Evans, Synthesis, 2005, 1333.

18 S. V. Ryabukhin, A. S. Plaskon, E. N. Ostapchuk, D. M. Volochnyuk and A. A. Tolmachev, Synthesis, 2007, 417, 417-427.

19 M. M. Hosseini, E. Kolvari, N. Koukabi, M. Ziyaei and M. A. Zolfigol, Catal. Lett., 2016, 146, 1040.

20 H. Naeimi and Z. S. Nazifi, Iran. J. Catal., 2018, 8, 249.

21 M. P. van der Helm, B. Klemm and R. Eelkem, Nat. Rev. Chem., 2019, 3, 491-508.

22 A. Khazaei, H. A. Alavi Nik and A. R. Moosavi-Zare, J. Chin. Chem. Soc., 2015, 62, 675.

23 A. Khazaei, H. A. A. Nik, A. R. Moosavi-Zare and H. AfsharHezarkhani, Z. Naturforsch., B: J. Chem. Sci., 2018, 73, 707.

24 G. Harichandrana, S. David Amalraj and P. Shanmugam, J. Iran. Chem. Soc., 2011, 8, 298.
25 H. Kiyani and F. Ghorbani, Res. Chem. Intermed., 2015, 41, 2653.

26 A. Kumar, D. Saxena and M. K. Gupta, RSC Adv., 2013, 3, 4610.

27 J. S. Yadav, M. K. Gupta, R. Jain, N. N. Yadav and B. V. S. Reddy, Monatsh. Chem., 2010, 141, 1001.

28 APHA, Standard Methods for the Experimentation of Water and Wastewater, American Public Health Association/American Water Works Association/Water Environment Federation, Washington DC, USA, 21st edn, 2005.

29 V. Vacek, Thermochim. Acta, 1980, 35, 181-185.

30 R. Biswas, D. Saha and R. Bandyopadhyay, Phys. Fluids, 2021, 33, 013103.

31 H. J. Lee and M. H. Kang, Nutr. Res. Pract., 2013, 7, 34-42.

32 H. Hosoda, H. Mori, N. Sogoshi, A. Nagasawa and S. Nakabayashi, J. Phys. Chem. A, 2004, 108, 1461-1464.

33 Y. I. Cho and S.-H. Lee, Int. Commun. Heat Mass Transfer, 2005, 32, 1-9.

34 H. Khabazzadeh, E. T. Kermani and T. Jazinizadeh, Arabian J. Chem., 2012, 5, 485-488.

35 J. Javidi, M. Esmaeilpour and F. N. Dodeji, RSC Adv., 2015, 5, 308-315.

36 A. Ghorbani-Choghamarani and P. Zamani, Chin. Chem. Lett., 2013, 24, 804-808. 